Archives de sciences sociales des religions

120 | octobre - décembre 2002

Varia

\title{
De l'effet des religions sur la mondialisation
}

Nathalie Luca

\section{OpenEdition}

Journals

Édition électronique

URL : http://journals.openedition.org/assr/760

DOI : $10.4000 /$ assr.760

ISSN : $1777-5825$

Éditeur

Éditions de l'EHESS

Édition imprimée

Date de publication : 1 octobre 2002

Pagination : 47-53

ISBN : 2-222-96725-2

ISSN : 0335-5985

Référence électronique

Nathalie Luca, « De l'effet des religions sur la mondialisation », Archives de sciences sociales des religions [En ligne], 120 | octobre - décembre 2002, mis en ligne le 24 octobre 2005, consulté le 30 avril 2019. URL : http://journals.openedition.org/assr/760 ; DOI : 10.4000/assr.760 


\title{
DE L'EFFET DES RELIGIONS SUR LA MONDIALISATION
}

\author{
À propos de : \\ SAMAMA (Claude-Raphaël), Développement mondial \\ et culturalités. Essai d'archéologie et de prospective \\ éco-culturales, Paris, Maisonneuve et Larose, 2001, \\ 373 p. (bibliogr., index, graphiques, tablx.). \\ LERAT (Christian), RIGAL-CELLARD (Bernadette), \\ Les Mutations transatlantiques des religions, Pessac, \\ Presses universitaires de Bordeaux, 2000, 377 p. \\ (bibliogr., illustr.). \\ CHAMPION (Françoise), dir., Ethnologie française, \\ "Les nouveaux mouvements religieux », Paris, PUF, \\ octobre-décembre, 2000/4, pp. 525-652.
}

La prise en considération de la mondialisation est devenue aujourd'hui incontournable pour l'ensemble des sciences sociales. La compréhension des faits politiques, économiques, culturels ou religieux passe par l'analyse des liens ou des césures transnationales. Les trois ouvrages sélectionnés ici portent un regard complémentaire sur les conséquences de ce processus, même si tous n'ont pas directement pour objet son étude. Seul celui de Claude-Raphaël Samama traite de l'expansion internationale du modèle économique occidental et, à travers ce dernier, de la culturalité qui l'a engendré. Cet économiste, également diplômé en philosophie et en psychologie, n'a pas segmenté les disciplines : il rétablit le lien entre sciences économiques, sociales et humaines, et s'inspire très largement de la problématique wébérienne, en donnant à la religion un rôle moteur dans les orientations des principales économies du monde. Son étude est cependant destinée à ses confrères, auxquels l'auteur adresse un message inquiet. Il les encourage à décloisonner leur discipline et à déplacer leur regard occidentalo-centré afin de percevoir les facteurs humains - les culturalités - qui structurent les modèles économiques. La problématique de ce livre n'est certes pas très originale pour les sociologues et anthropologues spécialistes des faits religieux. Sa perspective théorique d'économiste apporte néanmoins de l'eau au moulin et donne une grille de lecture des deux autres ouvrages collectifs sélectionnés, composés d'études de terrain, qui sont 
autant d'exemples et de contre-exemples à l'essai de Samama. Seuls, ceux qui répondent au modèle proposé par Samama ont été sélectionnés ici, bien que tous méritent l'attention des lecteurs intéressés par l'interminable voyage des religions et par l'étude de leur flexibilité.

Selon Claude-Raphaël Samama, le modèle économique occidental (pour lequel le développement est lié par équivalence à la croissance infinie, sans que ne soit jamais posée la question de la finalité) étend inexorablement ses tentacules à travers le monde, sans se soucier de la déstabilisation, sinon de la destruction de l'identité culturelle que cette invasion brutale peut provoquer en maints endroits. Il réduit implacablement tous ceux qui lui résistent et crée de la sorte une dramatique homogénéisation planétaire - confusément nommée mondialisation. Pour éviter la réduction ou résorption de groupes humains, " catastrophe possible dans un proche avenir », l'auteur réfléchit à une économie plus humaine, capable de respecter des critères éthiques, des environnements naturels et sociétaux, une économie guidée par une «conscience civilisationnelle».

Pour démontrer l'occidentalo-centrisme des études économiques, il s'interroge sur la définition du sous-développement. Il constate que ce concept apparaît alors même que s'achève la période coloniale en Afrique et en Asie, comme si les problèmes de famine, de pauvreté, ou d'industrialisation des pays pauvres étaient soudainement apparus aux ex-pays colonisateurs. Il en conclut que la figure du sous-développement n'est pas une réalité intrinsèque, non-historique mais résulte d'un rapport à une «norme occidentale » impliquant un certain type de croissance et de distribution. Les pays dits sous-développés sont ceux qui se situent en-deçà de cette norme. Qu'ils puissent faire le choix d'un autre type de croissance, ou référer à d'autres valeurs ontologiques de civilisation n'entrent pas en considération : seule importe l'expansion du modèle occidental, à laquelle il ne peuvent résister, du fait de leur dépendance à la technologie, au capital ou à l'organisation politique des pays les plus «développés ». Ainsi, la revendication d'universalité qui porte l'histoire de l'Occident ne s'achève-t-elle pas à la fin de la colonisation. Bien au contraire, sa volonté hégémonique se poursuit autrement et continue de réduire l'Autre au même.

Pourtant, l'ambition de l'ouvrage est précisément de présenter des modèles économiques non-occidentaux capables de résister au rouleau compresseur occidental, et en passe de dépasser le modèle économique tentaculaire. Il lie cette résistance à des facteurs religieux, culturels, éthiques, sociaux (ensemble qu'il réunit sous le vocable de culturalité), radicalement différents de ceux de la tradition religieuse occidentale judéo-chrétienne, mais parfaitement capables de s'approprier et de féconder les valeurs économiques reçues de l'Ouest. Ils représentent ainsi une échappatoire possible à l'homogénéisation par le modèle occidental.

Une telle démonstration oblige nécessairement l'auteur à prendre ses distances avec la thèse marxiste matérialiste d'explication des inégalités économiques. Elle le rapproche au contraire de la thèse wébérienne de la naissance du capitalisme occidental où l'on voit combien la religion influence voire surdétermine l'orientation économique des peuples qui la pratiquent. Il regrette cependant que Weber n'ait pas saisi les «éléments fertiles des idéaux religieux et culturalistes extrêmes-orientaux dans leur rapport au développement rationnel de l'économie et du capital », ou à tout le moins, qu'il ne soit pas allé jusqu'à " faire de ces éléments des facteurs suffisants pour aboutir au capitalisme tel qu'il s'est développé en Occident ». 
L'Inde, la Chine et le Japon sont pour lui trois exemples incontournables d'expression de capitalismes non occidentaux. En s'y référant, il espère expliquer le développement, voire le dépassement économique d'aires géographiques et culturelles non occidentales. Pour y parvenir, il fuit la démarche fonctionnaliste qui consiste à se référer à des évolutions historiques ou chronologiques. Il se place davantage dans une perspective structuraliste, visant à formaliser une "systémique anthropologique ». Il apparaît cependant que malgré l'excellence des hypothèses de C.R. Samama, sa démonstration n'aboutit pas vraiment, peut-être tout simplement parce que son survol, certes tout à fait louable et de qualité, des cultures extrême-orientales, ne lui permet pas de tisser tous les liens entre les traditions religieuses qu'il décrit et leur insertion et transformation dans les cultures qui les ont adoptées. Il n'en demeure pas moins que ses réflexions et intuitions seront précieuses pour les orientalistes qui souhaiteront enrichir l'argumentation.

Celle-ci commence par le bouddhisme, «porteur d'une conception spirituelle inédite en Occident » et en tout point opposée aux valeurs liées à l'émergence du capitalisme occidental : vacuité de l'esprit, détachement du monde et lutte contre le désir sont associés chez Weber à la stagnation au plan économique. Pourtant, certains des pays qui le pratiquent sont aujourd'hui parmi les plus puissants du monde. Comment expliquer ce paradoxe, une fois admis que la thèse du mimétisme asiatique ne peut justifier l'avance que l'Asie prend désormais sur l'Occident? L'auteur indique judicieusement le chemin des syncrétismes, non emprunté par Weber, mais sans l'exploiter véritablement. Il signale l'apparition des nombreuses sectes qui se sont emparées du bouddhisme tout au long de l'histoire du Japon, mais sans montrer comment les valeurs portées par le bouddhisme se sont trouvées inversées, et dès lors bien plus compatibles avec le développement économique. Il n'en demeure pas moins qu'il met le doigt sur des éléments-clé de la compréhension de l'envol économique du Japon, peu explorés jusqu'à ce jour.

L'auteur constate également la capacité de l'Inde à se rapprocher du modèle économique occidental. Ce pays n'en perd pas pour autant les caractères de sa profonde identité, marquée par un système de castes paradoxalement peu favorable à un envol économique. La survie de cette identité dans un contexte qui devrait lui être hostile permet à C.R. Samama de conclure à « la capacité adaptative de la culturalité indienne ». Néanmoins, les liens entre cette culturalité et les capacités économiques de ce pays restent flous.

Son approche du rapport entre le mode économique de la Chine et sa culture confucéenne est de loin le plus convaincant. Les valeurs confucéennes placent l'individu au cœur de la société, de son groupe et de sa famille (et ancêtres) en dehors desquels il ne se conçoit pas, et contre lesquels il ne saurait agir. De fait, l'intérêt collectif prime sur l'intérêt individuel et encourage le dévouement, le sacrifice de soi, le respect du bien commun, de l'ordre et des hiérarchies, autant de valeurs favorables à l'organisation du travail et en affinité organique avec une idéologie communiste « qui duplique dans la modernité une sorte de paradigme impérial ». Tout aussi bien, les performances économiques capitalistes chinoises - celles de Hong-kong, Singapour, Taïwan ou encore celles d'individus vivant en diaspora - « ne peuvent être comprises autrement qu'en référence à un corpus de valeurs qui, sous des formulations certes tout autres, n'est pas loin de ce que met en jeu le processus wébérien $»$. 
L'auteur termine sa démonstration en prenant pour contre-exemple un univers religieux définitivement hostile aux valeurs occidentales : l'islam. Il explique que la soumission des musulmans à la Parole du prophète et à la communauté de croyants exclut la possibilité d'individuation terrestre et de destinée séparée de l'homme se réalisant par les œuvres propres d'une vocation mondaine. La pragmatique économique est ainsi très différente de celle des pays occidentaux. "L'islam lie l'homme à un Dieu séparé qui ne demande que de rester à sa place à sa créature admirable mais statique. On pourrait aussi dire admirable donc statique, c'est-à-dire, à préserver en son état créée ». Une telle lecture donne une clé - dont j'ignore l'originalité - de la résistance du fondamentalisme musulman au capitalisme occidental - dont l'aspect sans doute le plus inacceptable à cet égard est d'avoir fait de l'homme un Dieu.

Enfin, C.-R. Samama lie le phénomène des sectes aux problèmes que pose le modèle occidental de l'économie: les valeurs et finalités du développement oubliées, l'individu se retrouve enchaîné à une croissance infinie où le sens de la vie s'est perdu. Les abus ou folies suicidaires de quelques groupes sectaires - en Occident mais également au Japon - prouveraient que ce modèle est en crise. Mais à ce titre, le modèle japonais n'apporte donc rien de meilleur. Voilà qui conduit la démonstration de l'auteur à l'échec : il y a peut-être d'autres culturalités qui supportent et s'approprient l'économie capitaliste pour en faire autre chose, mais si l'on veut s'en inspirer, mieux vaut s'assurer qu'elles ne mènent pas aux mêmes failles... Sinon à quoi bon savoir que d'autres routes conduisent à la même impasse?

En réalité, je doute que l'hypothèse sur laquelle repose le travail de C.-R. Samama soit tout à fait solide. S'il apparaît comme une évidence que l'Occident et, à travers lui, plus encore les États-Unis, partagent une tentation hégémonique qui peut faire redouter la perte d'identité de l'Autre, il apparaît également que les capacités de rebondissement, de survie et d'adaptation des cultures locales sont, à l'instar de la "culturalité indienne » décrite par l'auteur, tout à fait étonnantes. Dans son analyse des cultures religieuses, Samama ne tient compte que des religions à écriture, visiblement convaincu qu'elles sont les seules à résister ou à s'adapter au capitalisme moderne. Les traditions - africaines notamment - dont il craint la disparition prochaine, sont vraisemblablement celles issues des cultures orales. En cela, il n'échappe pas au regard occidentalo-centré qu'il reproche à ses collègues. L'ouvrage dirigé par Christian Lerat et Bernadette Rigal-Cellard, bien que construit autour d'une autre problématique, présente une richesse d'exemples qui peuvent tout à la fois éclairer et indiquer les limites de la problématique de C.-R. Samama. Il est une réponse possible, anthropologique, à son essai.

Ce recueil d'articles a une visée plus limitée que celle de Samama puisqu'il ne s'intéresse qu'à la diaspora des religions issues de l'Ancien et du nouveau Monde. Mais il part lui aussi du postulat que la facilité d'adaptation des religions en provenance des États-Unis s'intègre dans le modèle expansionniste de la première puissance planétaire. C'est dans cette perspective qu'il rend compte des échanges, des influences et des écarts entre les deux rives de l'Atlantique, constatant d'emblée que « les sociétés indigènes converties façonnent le contenu spirituel et cérémoniel des religions importées et les renvoient métamorphosées par-delà l'Occident $»$. C'est ce second postulat que Samama a ignoré, ou du moins ne l'a-t-il envisagé que pour les quelques puissances capitalistes extrême-orientales qu'il décrit. 
Certains articles appuient incontestablement la thèse de Samama, bien que tous établissent une nette distinction entre l'Europe et les États-Unis, distinction délibérément négligée par C.-R. Samama. Ainsi, la première partie de l'ouvrage, intitulée « les métamorphoses de l'islam et du judaïsme aux États-Unis », met en lumière combien l'intégration des populations issues de ces deux religions fragilise leur culture irrésistiblement américanisée, ou conduite à l'exclusion : l'Autre ne trouve sa place qu'en perdant ses caractéristiques propres. Sadok Damak note ainsi que les Arabes-musulmans, pour gagner une dignité, et s'inscrire dans une «culture judéo-christiano-musulmane » ont rendu la religion islamique compatible avec le christianisme et adaptable à la vie moderne. Pour se faire accepter de leurs co-citoyens, il leur a donc fallu faire entrer l'islam dans le modèle et la «culturalité » capitalistes occidentaux. Véronique Eleftariou-Perrin note également combien, l'incompatibilité de la culture moderne américaine et de ses plaisirs profanes, avec l'exigence des normes juives a fait éclater les communautés immigrées du Centre-Est européen par un rapide processus de déjudaïsation.

Mais c'est sans aucun doute la seconde partie, intitulée «Les échanges entre l'Afrique, l'Europe et les Amériques », qui est heuristiquement la plus féconde. Je m'arrêterai ici tout particulièrement sur l'article de Richard Djiropo, non seulement parce qu'il est un contre-exemple de l'hypothèse de Samama, mais aussi parce que simultanément, la problématique de ce dernier en affine la compréhension. L'article étudie «les confluences du vodou et de la chrétienté en Haïti », et s'intéresse donc à l'histoire culturelle d'une colonie peuplée d'esclaves noirs issus de vingt et une tribus africaines différentes, qui ont conservé pour tout bagage le vodou. Ces esclaves baptisés aussitôt arrivés, devenaient de fait chrétiens. Étrangers aux symboles de cette religion, ils reconstruirent cependant leur identité autour $\mathrm{du}$ vodou. Il fut à l'origine d'un acte politique fondamental : celui de l'indépendance et de la naissance de la République d'Haïti en 1804. Pourtant, au moment même de construire ce nouvel État, les Haïtiens firent le choix de la religion catholique et inscrivirent la foi chrétienne, celle des colons, dans la constitution de leur pays, maintenant volontairement le vodou dans la clandestinité : "pratiquer le vodou pouvait être passible d'une peine de prison assortie d'une amende ».

Pour toute explication de ce paradoxe, l'auteur souligne que l'être haïtien s'est construit sur une double identité africaine et européenne. Néanmoins, en se replaçant dans la problématique de Samama, il semble possible d'apporter une explication structurelle à cette contradiction. Ces tribus africaines rassemblées sur cette île n'avaient pas de culture commune. Elles n'avaient pas davantage idée de ce que pouvait être un État, notion tout aussi étrangère pour elles que l'était la religion catholique. Comment donc auraient-elles pu faire émerger un pays sans se calquer sur la "culturalité occidentale », - et sur la religion catholique qui en est un élément constitutif - dont est issue la notion d'État ? Ces tribus arbitrairement réunies n'ont pu s'unir qu'en se fondant dans l'esprit du colon et en s'adaptant à ses propres règles : ainsi l'on voit comment le rouleau compresseur occidental a pu être à l'œuvre dans la décolonisation, et détruire - en apparence au moins - l'identité culturelle des sociétés indigènes, ce que constate Samama sans l'étayer d'exemples. Cependant, une fois intégrée la conscience étatique, le vodou est réapparu, «non plus comme une honte, mais comme un pilier de leur identité, au même titre que le catholicisme ». Plus encore, les chercheurs constatent que tout en gardant les formes, le vodou a coulé dans la religion occidentale la matière africaine : la compres- 
sion n'a été qu'apparente. Elle n'a duré que le temps de l'adaptation. Cette résistance inattendue nuance donc les craintes de Samama de voir disparaître les cultures les moins compatibles avec le modèle occidental, sans remettre toutefois en cause l'homogénéisation du système politique et économique.

Un article de Jack Corzani portant sur « les avatars du catholicisme en Guadeloupe et en Martinique » vient confirmer cette contradiction apparente. Là encore, l'Église a gardé son esprit colonialiste, conservateur et raciste sans pour autant être rejeté par les Noirs après l'abolition de l'esclavage. Le modèle civilisationnel qu'elle leur offrait semblait capable d'anéantir toute identité créole. Celle-ci, cependant, a su s'exprimer à travers les cérémonies catholiques elles-mêmes, obligeant l'Église à de véritables contorsions pour entrer dans le moule culturel local. Le modèle occidental s'est donc imposé sans être pour autant capable de résorber l'essence créole.

Mais l'on peut faire un pas de plus : non seulement le rouleau compresseur occidental ne touche bien souvent que l'apparence des cultures locales, mais encore, la remarquable adaptation de ces cultures au modèle étranger leur permet désormais de s'exporter. Elles travaillent ainsi la culturalité occidentale, dont les traits et les limites s'obscurcissent. «La diffusion du pentecôtisme brésilien en France et en Europe », présentée par Marion Aubrée, aurait pu être un excellent exemple de cette intrusion d'éléments exogènes au modèle tentaculaire. On voit comment l'arrivée de l'Église Universelle du Royaume de Dieu en Europe a pu effrayer certains pays au point de les amener à enquêter sur ce groupe issu tout à la fois des principes du modèle économique occidental - et donc d'une croissance non rapportée à une finalité - et du substrat culturel historique des Brésiliens - ne serait-ce que par l'intégration de la dimension visuelle dans un groupe qui continue à se réclamer du protestantisme, par définition iconoclaste. Marion Aubrée indique, sans l'analyser cependant, le succès de cette Église auprès d'un groupe d'Antillais français. Peut-être aurait-il été possible de lier cette attirance à des éléments communs entre les cultures antillaise, africaine et brésilienne et de s'interroger ainsi sur la façon dont les cultures non occidentales se protègent et s'étendent en se camouflant derrière la caricature même de ce qui est, pour Samama, le modèle économique occidental.

Enfin, l'unique et très riche numéro d'Ethnologie française que Françoise Champion a dirigé sur les nouveaux mouvements religieux pourrait être une dernière réponse à adresser à l'ouvrage de Samama. Ce numéro, dont on ne pourra malheureusement détailler les articles, traite en effet des groupes qui se développent aujourd'hui en Occident, "en dehors de la matrice chrétienne ", à partir d'apports religieux non occidentaux. Ces mouvements, indique Françoise Champion, sont précisément «en rupture par rapport aux enjeux qui structurent la tradition chrétienne, et donc, la typologie wébéro-troeltchienne ». Néanmoins, leur organisation est en affinité « avec les formes de groupements contemporains hors religion, dans la vie culturelle, politique ou sportive », et peuvent participer ainsi du modelage de la culturalité occidentale. Elle constate combien la notion bouddhiste de karma conduit simultanément à la responsabilisation des individus et au retour de « la toute-puissance magique ». Les adeptes s'opposent alors à l'un des éléments constitutifs de la culturalité occidentale, la rationalité, sans pour autant cesser d'être en affinité avec la société dominante dans laquelle ils cherchent parfois à s'adapter le mieux possible. Ils demeurent ainsi dans le modèle capitaliste occiden- 
tal, mais sans en partager les éléments constitutifs. Ils le chargent d'un nouveau bagage, une tradition exogène qui en perturbe les contours. Car, constate enfin l'auteur, s'il y a effectivement une globalisation du modèle économique occidental, il n'en va pas de même pour les religions, et l'on pourrait bien s'interroger sur une « orientalisation » de l'Occident (ce dont traite notamment l'article stimulant de Patricia Birman). Cette perspective complexifie d'emblée la problématique présentée dans l'ouvrage de Samama: le bloc occidental ne submerge peut-être pas tout et la culturalité dont il est issu n'est sans doute pas plus imperméable que les autres. L'homogénéisation qu'il redoute ne serait alors que d'apparence. Il n'en demeure pas moins que le danger de la perte de profondeur et de sens du substrat culturel reste de mise. Ainsi par exemple, en parvenant en Occident, le zen que décrit Alioune Koné, ou le néo-hindouisme, qu'analyse Véronique Altglas, se transforment tout autant que le catholicisme en Haïti. La valse de ces religions défait leur attachement culturel. À force de transformer, de coller, d'échanger, c'est peut-être alors la notion même de culturalité, occidentale et non occidentale, qui risque d'éclater pour se reconstituer autrement.

Nathalie LUCA

Centre d'Études Interdisciplinaires des Faits Religieux - CNRS 
